\title{
Blood Pressure Monitoring
}

1.6 Relationship Between Ambulatory Artery Stiffness Index and Glomerular Filtration Rate in Essential Hypertension

G. Mule',1 S. Cottone,1 P. Cusimano,1 F. Incalcaterra, ' M. Giandalia, 1

M. Costanzo,1 A. Palermo,1 E. Nardi,1 C. Geraci,1 R. Costa,2 G. Cerasola

(1) Università di Palermo - Cattedra di Medicina Interna e Cattedra di

Nefrologia, Pa Palermo; (2) Università di Palermo - UO di Medicina Nucleare,

Palermo, It Italy

Introduction: Arterial stiffness and mild renal dysfunction are predictors of cardiovascular morbidity

and mortality. Recently, the Ambulatory Arterial Stiffness Index (AASI) has been proposed as a surrogate index of arterial stiffness. The aim of our study was to assess the relationships between AASI and glomerular filtration rate (GFR) in a group of uncomplicated essential hypertensive patients.

Methods: A total of 143 untreated essential hypertensive subjects (mean age: $44 \pm 12$ years; men

$57 \%$ ), with serum creatinine less than $1.5 \mathrm{mg} / \mathrm{dl}$, were enrolled. AASI was calculated as one minus the regression slope of diastolic on systolic blood pressure (BP) obtained by individual 24-h BP recordings. GFR was computed from the scintigraphic determination of the technetium- $99 \mathrm{~m}$ diethylenetriaminepentaacetic acid uptake within the kidneys, by the Gates' method.

Results:Essential hypertensive patients with AASI above the median value $(\mathrm{n}=71)$ had lower GFR than those with AASI below the median $(\mathrm{n}=73)(98.3 \pm 31 \mathrm{vs} 122.4 \pm 32 \mathrm{ml} / \mathrm{min} / 1.73 \mathrm{~m} 2 ; \mathrm{p}=$ $0.000008)$. This difference held even after adjustment for age and gender. The linear regression analysis disclosed a significant inverse correlation between AASI and GFR $(r=-0.30 ; p=0.00027)$ that was confirmed (beta $=-0.20 ; \mathrm{p}=0.01$ ) in a multiple regression model including, as independent variables, besides GFR, age, gender, HDL cholesterol, body mass index, 24-h mean BP and nocturnal reduction of diastolic BP.

Conclusions:Arterial stiffness, as estimated by AASI, is inversely related to GFR in uncomplicated essential hypertension and may help to explain the increased cardiovascular risk associated with mild renal dysfunction. 